\title{
Gender difference in health issues and cognitive functions among an Egyptian normal elderly population
}

\author{
Enas Alsayyad* (D), Azza Abbas Helmy, Nirmeen A. Kishk, Marwa Farghaly, Amany H. Ragab and \\ Shaimaa Ibrahim El-Jaafary
}

\begin{abstract}
Background: Aging is associated with changes in cognitive functions. However, many other factors may affect cognitive functions and this interaction needs further assessment.

Objectives: To detect gender differences in sleep quality, nutritional status, and health-related quality of life and their impact on performance in verbal fluency tasks among apparently healthy elderly.

Subjects and methods: The study was conducted on 102 normal aged subjects, 51 males and 51 females. Subjects were divided according to age into group $\geq 60$ years and group $<60$ years as a control. They were subjected to clinical assessment, Medical outcome study Short-Form 36-item Health Survey, Pittsburgh sleep quality index, mini nutritional assessment and Category Verbal fluency for animals and girls' names.

Results: Among the older group, females had significantly poorer physical and mental health, sleep quality and nutritional status than males ( $p$ value $0.001,0.003,0.012$, and 0.014 , respectively). Older females had significantly lower performance in verbal fluency (girls' names) compared to younger females ( $p$ value 0.013 ), but no significant gender difference was found among the older group. Verbal fluency tasks are correlated to the level of education in both males and females ( $r 0.392$ and $0.42, p$ value 0.029 and 0.019 , respectively), However, in older males, it is also correlated to sleep latency ( $r 0.41$ and $p$ value 0.021 ).
\end{abstract}

Conclusion: Older females had poorer sleep quality, lower health-related quality of life and lower nutritional status. No gender difference was found in verbal fluency tasks. Although no single variable could independently affect verbal fluency, education remains the main player in the difference in performance.

Keywords: Normal aging, Verbal fluency, Gender difference, Sleep, Health-related quality of life, Nutrition status

\section{Introduction}

Successful aging is defined as the absence of disease or a minimal alteration of physiological functions and musculoskeletal system [1]. Aging is not only associated with physical changes, but it is also associated with changes in cognitive functions. Normal age-related cognitive decline can be difficult to distinguish from the early stages of disease-associated impairment [2]. The clinical manifestation of these changes can be subtle and vary considerably between individuals. Cognitive functions that decline with aging are executive functions, information

\footnotetext{
* Correspondence: enas.alsayyad@kasralainy.edu.eg

Neurology Department, Cairo University, Al-Saraya Street, El Manial, Cairo 11956, Egypt
}

processing speed, attention and encoding, and retrieval of new memories but do not prevent the performance of daily activities [3].

Studies demonstrating gender differences in neurocognitive performance showed that females, on average, perform better than males on tests of fluency, verbal memory, fine motor skills, and perceptual speed, while males tend to perform better on tests of visual memory, visuospatial abilities, and problem-solving [4]. Cognitive changes can be impacted by non-neurologic factors that are also affected by normal aging. Age-related cognitive changes may be associated with poor sleep, which is in some cases a treatable condition [5]. In addition, nutritional status may affect the normal aging process. The 
elderly have special dietary requirements for maintaining good health and doing various activities [1]. A healthy and well-balanced diet is crucial for preventing potential cognitive decline [6].

In the elderly, health-related quality of life is a multidimensional concept including domains related to physical, mental, emotional, and social functioning [7]. Many factors are thought to influence quality of life, including physical health and functioning, self-esteem, self-efficacy, autonomy, coherence, physical environment, social relationships, economics, and spirituality [8].

The main feature in the Egyptian population over the last decades is a gradual increase in life expectancy for both males and females [9]. Therefore, assessing the cognitive functions and factors possibly affecting the cognitive status in the elderly can help in the development of interventions that maintain cognitive performance. Accordingly, this study aimed to detect gender differences in fluency tasks among elder Egyptians and to study the impact of sleep quality, nutritional status, and healthrelated quality of life on cognitive performance among apparently healthy elderly.

\section{Subjects and methods}

The current study is an observational, cross-sectional study, conducted on 102 normal aged subjects, 51 males and 51 females, aged $\geq 50$ years. Those subjects were categorized according to age, based on WHO report [10] into 2 groups, group aged $\geq 60$ years and the other group aged $<60$ years, as a control group. Male:female ratio was 1:1. In both younger and elder groups, male and female subgroups were age-matched.

Participants should have the ability to read, write, and do simple calculation. They should have a score $\geq 24$ on mini-mental state examination, to exclude dementia, [11] and have a score $<10$ on Hamilton Rating Scale of Depression, to exclude depression [12]. Females included should be menopausal. All subjects included had no vascular risk factors. Subjects included should have no history of memory complaints or cognitive dysfunctions. Participants with a history of drug intake known to affect cognition or mentality or with the previous history of a neurological condition known to cause cognitive impairment were excluded from this study.

Subjects were subjected to clinical assessment, medical outcome study Short-Form 36-item Health Survey, Pittsburgh sleep quality index, mini nutritional assessment, and Category Verbal fluency for animals and girls' names.

Categorical verbal fluency tasks are more appropriate to be used in the Egyptian population to overcome the high percentage of illiteracy in elders. Furthermore, phonemic fluency tasks showed no diagnostic superiority in the Egyptian population [13]. So, we used categorical (animals and girls' names verbal fluency tasks). This test was used as a measure of executive functions and semantic fluency [14]. The sum of all correct admissible words for the tested semantic category were recorded.

For the assessment of health-related quality of life (HRQoL), medical outcome study (MOS) Short-Form 36 Health Survey (SF-36) was used [15]. It is a 36-item questionnaire which measures Quality of Life (QoL) across eight domains, which are both physically and emotionally based. A summary of physical QoL (Physical Component Summary; PCS) and emotional QoL (Mental Component Summary; MCS) was calculated by the mean average of all of the physically relevant questions and of all of the emotionally relevant items. We used an Arabic version which had been validated as equivalent to the US English version [16].

Pittsburgh Sleep Quality Index (PSQI) was used to measure the quality and patterns of sleep in older adults [17]. We used an Arabic translated version of PSQI [18]. It differentiates "poor" from "good" sleep. Higher scores indicate worse sleep quality as a global sum of " 5 " or greater indicates a "poor" sleeper.

Mini Nutritional Assessment-Short form (MNA), which is a screening and assessment tool for the identification of malnutrition, was used for assessment of nutritional status. We used mini nutritional assessmentArabic version [19]. The score of 12-14 points indicates normal nutritional status, $8-11$ points indicates at risk of malnutrition while score of $0-7$ points indicates malnutrition.

\section{Statistical analysis}

Results were evaluated statistically by the Statistical Package for the Social Sciences (SPSS) version 23. Normality of data was tested by the Kolmogorov-Smirnov test. To describe the data, frequency (percent) and mean \pm SD were used. $T$ test and Pearson correlation tests were used for comparisons and correlations, respectively. Linear regression models were used to further analyze relations. $p$ values less than 0.05 were considered statistically significant.

\section{Results}

Female participants aged $\geq 60$ years had a statistically significant lower level of education than males of the same age $(p$ value $=0.001)($ Table 1$)$.

According to MOS Short-Form 36-item health survey (SF-36), female participants aged $\geq 60$ years had significantly lower scores than males of same age, in total physical component $(p$ value $=0.001)$ and total mental components $(p$ value $=0.003)$; where mean total physical component was $63.2 \pm 26.35$ and $84 \pm 14.61$ respectively. While the mean total mental component was $64.83 \pm 22.75$ and $80.41 \pm 16.8$ respectively. 
Table 1 Demographic characteristics of all participants

\begin{tabular}{|c|c|c|c|c|}
\hline \multirow[t]{3}{*}{$\begin{array}{l}\text { Participants } \\
\text { Aged }<60 \text { years }\end{array}$} & Demographic characteristics & $\begin{array}{l}\text { Males } \\
n=20\end{array}$ & $\begin{array}{l}\text { Females } \\
n=20\end{array}$ & $p$ value \\
\hline & Age (mean \pm SD) & $54.15 \pm 3.21$ & $53.45 \pm 2.5$ & 0.45 \\
\hline & Years of education (mean \pm SD) & $7.65 \pm 4.75$ & $5.6 \pm 3.28$ & 0.12 \\
\hline \multirow[t]{3}{*}{$\begin{array}{l}\text { Participants } \\
\text { Aged }<60 \text { years }\end{array}$} & Demographic characteristics & $\begin{array}{l}\text { Males } \\
n=31\end{array}$ & $\begin{array}{l}\text { Females } \\
n=31\end{array}$ & $p$ value \\
\hline & Age (mean \pm SD) & $67.29 \pm 5.03$ & $65.39 \pm 4.65$ & 0.12 \\
\hline & Years of education (mean \pm SD) & $9.32 \pm 6.18$ & $4.87 \pm 3.16$ & $0.001^{*}$ \\
\hline
\end{tabular}

${ }^{*} p$ value $<0.05$ is considered statistically significant

Females $\geq 60$ years had significantly longer sleep latency and worse daytime functioning than males in the same age group, and significantly poorer sleep quality (higher total PSQI score) mean $4.68 \pm 2.92$ and $6.84 \pm 3.74$, respectively $(p$ value $=0.01)($ Fig. 1$)$.

Female participants aged $\geq 60$ years obtained significantly lower scores in the mini nutritional assessment screening than males ( $p$ value $<0.001$ ) with a mean 11.42 \pm 2.17 and $13.16 \pm 1.21$, respectively. Where a sum of 15 females (48\%) was malnourished or at risk of malnutrition in comparison to 5 males (16\%), $p$ value $=0.012$.

Female participants aged $\geq 60$ years showed significantly lower performance in verbal fluency (girls' names) than younger females ( $p$ value 0.013$)$. There was no significant difference in comparing male subgroups. No gender difference was found between both older groups (Table 2).



Correlations between various studied parameters showed that performance in fluency tasks was correlated with education in both male and female subgroups ( $p$ value $=0.029$ and 0.019 , respectively). In older females, it was correlated with age $(r=-0.389$, $p=0.026$ ) (Table 3). In older males, shorter sleep latency was associated with better performance in verbal fluency tasks ( $r=-0.412, p=0.021$ respectively). Sleep parameters showed no significant correlations with verbal fluency tasks in older females. Physical and mental components did not affect the cognitive performance in both male and female subgroups. MNA scores did not show any correlation with verbal fluency test in either older males or females (Table 4).

Multiple linear regression analysis using stepwise technique showed that, in participants aged $\geq 60$ years, female gender is an independent variable affecting nutritional status $(r=0.45$ and $p$ value $=<$ 0.001). Otherwise, no gender effect on other studied parameters.

Table 2 Comparison between participants in performance in verbal fluency tasks

\begin{tabular}{llll}
\hline Verbal Fluency Tasks & Females $<60$ years & Females $\geq 60$ years & $p$-value \\
& $n=20$ & $n=31$ & \\
& Mean $\pm S D$ & Mean $\pm S D$ & \\
Animals & $16.1 \pm 3.71$ & $14.39 \pm 3.92$ & 0.12 \\
Girls names & $18.65 \pm 4.75$ & $15.29 \pm 4.39$ & $0.013^{*}$ \\
& Males $<60$ years & Males $\geq 60$ years & $p$-value \\
& $n=20$ & $n=31$ & \\
& Mean $\pm S D$ & Mean $\pm S D$ & \\
Animals & $15.85 \pm 4.88$ & $15.26 \pm 3.86$ & 0.63 \\
Girls names & $17.60 \pm 3.41$ & $16.87 \pm 4.8$ & 0.55 \\
& Males $\geq 60$ years & Females $\geq 60$ years & $p$-value \\
& $n=31$ & $n=31$ & \\
Animals & Mean $\pm S D$ & Mean $\pm S D$ & \\
Girls names & $15.26 \pm 3.86$ & $14.39 \pm 3.92$ & 0.38 \\
${ }^{*} p$ value $<0.05$ is considered statistically significant & 0.8 \\
\hline
\end{tabular}

${ }^{*} p$ value $<0.05$ is considered statistically significant 
Table 3 Correlation between age, educational level and verbal fluency test

\begin{tabular}{|c|c|c|c|c|c|c|c|c|}
\hline \multirow{3}{*}{$\begin{array}{l}\text { Verbal Fluency } \\
\text { Tasks }\end{array}$} & \multicolumn{4}{|c|}{ Males $\geq 60$ years } & \multicolumn{4}{|c|}{ Females $\geq 60$ years } \\
\hline & \multicolumn{2}{|l|}{$\overline{\text { Age }}$} & \multicolumn{2}{|c|}{ Years of education } & \multicolumn{2}{|l|}{ Age } & \multicolumn{2}{|c|}{ Years of education } \\
\hline & $r$ & $p$-value & $r$ & $p$-value & $r$ & $p$-value & $r$ & $p$-value \\
\hline Animals & -0.285 & 0.12 & -0.089 & 0.635 & 0.341 & 0.06 & 0.085 & 0.65 \\
\hline Girls' names & -0.354 & 0.05 & 0.392 & $0.029^{*}$ & -0.389 & $0.026^{*}$ & 0.42 & $0.019^{*}$ \\
\hline
\end{tabular}

${ }^{*} p$ value $<0.05$ is considered statistically significant

\section{Discussion}

Gender effects on cognitive functions are modulated by multiple neurological factors such as hormonal sex differences, genetic factors, vascular lesions, brain maintenance, and cognitive reserve [20]. Executive functions are vulnerable to white matter injury [21]. Normal aging is associated with a decrease in white matter volume, composition, and integrity. These changes are more obvious in females [22].

The wide-spread use of verbal fluency tasks is because they afford rapid and reliable assessment of both verbal ability (VA) and executive ability (EA) [23]. A recent study was done on 112 Egyptian subjects (normal cognition control group $(n=79)$ and clinically demented group $(n=32)$ had found that semantic category (animals, vegetables and names) are appropriate to be used as culture-oriented and non-education based verbal fluency tests [13].

The pattern of gender differences in the category fluency of the healthy elderly is not consistent. Some studies found a female advantage [24], while Wiederholt and colleagues [25] found a male advantage in verbal category fluency in a sample of 54-95 years old population. Others found no gender differences at all [26]. The last studies were consistent with our results, as no significant difference in verbal fluency between males and females was found in the present study.

One of the most widely used instruments to assess health-related quality of life is the MOS SF-36 health survey. The SF-36 enables the investigation of healthrelated quality of life, addressing multiple dimensions: physical functioning, role of limitation due to physical problem (role-physical), bodily pain, general health, vitality, social functioning and emotional wellbeing, and role of limitation due to emotional problem (role-emotional) [27]. In the present study, older females had significantly lower physical and mental component scores than older males.

These results were consistent with previous studies that showed that older females had a lower healthrelated quality of life in general or in some domains $[27,28]$. These differences could be attributed to living longer, more disability, and more health problems reported by women in comparison to men. Older women are also, more likely to live alone, that has been associated with frailty, lower satisfaction, and lower-income level [29].

Table 4 Correlation between HRQol, PSQI, MNA scores, and verbal fluency tasks among older males and older females

\begin{tabular}{|c|c|c|c|c|c|c|c|c|}
\hline \multirow[t]{4}{*}{$\bar{B}$} & \multicolumn{8}{|c|}{ Verbal fluency tasks } \\
\hline & \multicolumn{4}{|c|}{ Older males } & \multicolumn{4}{|c|}{ Older females } \\
\hline & \multicolumn{2}{|l|}{ Animals } & \multicolumn{2}{|c|}{ Girls names } & \multicolumn{2}{|l|}{ Animals } & \multicolumn{2}{|c|}{ Girls names } \\
\hline & $r$ & $p$ value & $r$ & $p$ value & $r$ & $p$ value & $r$ & $p$ value \\
\hline \multicolumn{9}{|l|}{$\overline{H R Q O L}$} \\
\hline Physical component & 0.097 & 0.603 & 0.154 & 0.409 & 0.108 & 0.564 & -0.219 & 0.236 \\
\hline Mental component & 0.343 & 0.059 & 0.226 & 0.222 & 0.055 & 0.768 & -0.25 & 0.174 \\
\hline Total PSQI & -0.066 & 0.724 & -0.338 & 0.063 & -0.146 & 0.379 & -0.234 & 0.205 \\
\hline QUAL & 0.088 & 0.637 & -0.315 & 0.084 & 0.21 & 0.25 & 0.126 & 0.499 \\
\hline LATEN & 0.042 & 0.824 & 0.41 & 0.021 & -0.245 & 0.185 & -0.147 & 0.431 \\
\hline DURA & -0.035 & 0.851 & 0.02 & 0.914 & -0.252 & 0.175 & -0.108 & 0.562 \\
\hline HSE & 0.022 & 0.906 & 0.022 & 0.906 & 0.006 & 0.975 & -0.212 & 0.252 \\
\hline DIST & 0.108 & 0.561 & 0.108 & 0.561 & -0.175 & 0.346 & -0.265 & 0.149 \\
\hline DAYDYS & 0.233 & 0.208 & -0.018 & 0.925 & -0.094 & 0.615 & -0.286 & 0.119 \\
\hline MNA screening score & -0.023 & 0.901 & 0.004 & 0.984 & 0.168 & 0.366 & 0.147 & 0.429 \\
\hline
\end{tabular}

HRQoL health-related quality of life, PSQI Pittsburg Sleep Quality Index, QUAL subjective sleep quality LATEN sleep latency, DURA sleep duration, HSE habitual sleep efficacy, DIST sleep disturbance, MED: use of medications, DAYDYS daytime dysfunction, MNA mini nutritional assessment

${ }^{*} p$ value $<0.05$ is considered statistically significant 
In Egypt, QoL of postmenopausal women was found to be the most affected compared to premenopausal and perimenopausal women. Also, QoL was found to be significantly related to age, educational level, and socioeconomic status of women [30] and family size [31]. So, older women with lower educational levels and low socioeconomic status are more liable to have a poor quality of life and vice versa. Also, gravidity had a significant relation to the quality of life [32].

Physical activity likely impacts cognition via multiple neurobiological mechanisms. As physical activity has been linked to alterations of neural gray and white matter volume, gray matter density, white matter microstructure, cerebral blood volume, functional MRI activation, and functional MRI connectivity [33]. Yet our study failed to find a correlation between the physical component and verbal fluency tasks.

PSQI assessed sleep quality over the last month [34]. Studies suggest that sleep quality plays a critical role in the preservation of cognitive functions in older adults and reducing the risk of dementia [35]. Our study showed older females had significantly poorer sleep quality (higher total PSQI score), longer sleep latency, and worse daytime functioning than males in the same age group. Only subjective sleep quality was significantly poorer in younger females than in younger males. Previous studies found that females had significantly poorer sleep quality (higher total PSQI score) than males. They had significant impairment in subjective sleep quality, sleep latency, sleep duration, and habitual sleep efficiency compared to males [36].

Sleep deficit in the elderly could be attributed to shrinkage of the ventrolateral preoptic nucleus (VLPO) of the hypothalamus with advancing age. The volume and cell number of the sexually dimorphic nucleus in preoptic area of the hypothalamus (SDN-POA) showed a dramatic decrease with aging [37]. Gender difference is sleep quality could be due to hormonal changes related to menopause symptoms and associated with physical, physiological and psychological changes that may increase the incidence of problems related to sleep [38]. In our study, poorer sleep quality was associated with lower cognitive performance. In older males, longer sleep latency was correlated to lower performance in verbal fluency.

In the present study, older females obtained significantly lower scores in MNA compared to males in the same age group. These results were consistent with results of a study conducted by Mahfouz and colleagues, [39] on 243 elderly Egyptian aged 60 years or more and concluded that females were more likely to be affected by malnutrition, as $9.8 \%$ of females were malnourished vs $6.6 \%$ males Also, these findings were in coherence with a study finding of Ghimire and colleagues [40] and
Majumder and colleagues [41] who concluded that the malnutrition was more prevalent among elderly female than male.

Many studies found that MNA total score was lower in the oldest than in the youngest subjects in both genders [42, 43]. Older people's vulnerability to malnutrition might be explained by many reasons including physiological and functional changes that occur with age, lack of financial support, and inadequate access to food. The functional status of the elderly, which is defined as their ability to carry out their day to day activities including preparation of food and intake, also is changed thereby affecting nutritional status [44]. Lower females' scores could be attributed to their role in the society and their financial dependency [44] and educational level [45] which eventually affects nutritional status. This was consistent with our results as older females had lower education levels than males.

Several studies showed that malnutrition and risk of malnutrition associated with a cognitive deficit in older adults [46]. In Egypt, Khater Abouelezz [47] found that those with a risk of malnutrition and malnourished had a significant poorer performance in cognitive tests. $\mathrm{Nu}$ trition has a crucial role in age-related cognitive decline. Multiple brain processes, including neurogenesis, synaptic plasticity, and neuronal connectivity, that underpin cognitive function are affected by nutrition. Therefore, nutrition could be used throughout life to enhance neurological function and brain health [48].

\section{Limitations and recommendations}

Patient selection was limited to those with no vascular risk factors nor medical conditions which is not the norm in this age group. We recommend studying a larger number of subjects with more variability in demographics and to assess more cognitive functions.

\section{Conclusion}

Older females had poorer sleep quality, lower healthrelated quality of life and lower nutritional status. No gender difference was found in verbal fluency tasks. Although no single variable could independently affect verbal fluency, education remains the main player in the difference in performance.

\section{Acknowledgments}

Not applicable

\section{Authors' contributions}

EA participated in study design, sequence alignment, collection and analysis of data and helped to draft manuscript. AH participated in study design, and helped to draft manuscript. NK participated in study design, and helped to draft manuscript. MF participated in study design and helped to draft

manuscript. AR participated in study design and helped to draft manuscript. SE participated in study design, sequence alignment, collection and analysis of data. All authors read and approved the final manuscript. 


\section{Funding}

This research received no specific grant from any funding agency in the public, commercial, or not-for-profit sectors.

\section{Availability of data and materials}

The datasets generated and/or analyzed during the current study are not publicly available due to the current Cairo University regulations and Egyptian legislation but are available from the corresponding author on reasonable request and after institutional approval.

\section{Ethics approval and consent to participate}

Informed written consent was taken from each patient. All data obtained from every patient were confidential and were not used outside the study. The patients have the rights to withdraw from the study at any time without giving any reason.

Our study was approved by the ethical committee of the Department of Neurology, Faculty of Medicine, Cairo University, on 11 January 2015, but Cairo University does not provide the approval reference number.

\section{Consent for publication}

\section{Not applicable.}

\section{Competing interests}

The authors declare that they have no competing interests.

Received: 21 October 2019 Accepted: 5 January 2020

\section{Published online: 14 January 2020}

\section{References}

1. El Zoghbi M, Boulos C, Amal AH, Saleh N, Awada S, Rachidi S, et al. Association between cognitive function and nutritional status in elderly: A crosssectional study in three institutions of Beirut-Lebanon. Geriatric Mental Health Care. 2013:73-81.

2. Ravdin L. Late Life Cognitive Disorders. Reference Module in Biomedical Sciences. 2014.

3. Madden DJ, Bennett IJ, Burzynska A, Potter GG, Chen NK, Song AW. Diffusion Tensor Imaging of Cerebral White Matter Integrity in Cognitive Aging. Biochim Biophys Acta. 2012;1822(3):386-400.

4. Torres A, Gómez-Gil E, Vidal A, Puig O, Boget T, Salamero M. Gender differences in cognitive functions and influence of sex hormones. Actas Esp Psiquiatr. 2006;34(6):408-15.

5. Altena E, Ramautar J, Van Der Werf Y, Van Someren E. Do sleep complaints contribute to age-related cognitive decline? Prog Brain Res. 2010:81-5.

6. Huijbregts P, EJM F, Räsänen L, Fidanza F, Alberti-Fidanza A, Nissinen A, Giampaoli S, et al. Dietary patterns and cognitive function in elderly men in Finland, Italy and The Netherlands. Eur J Clin Nutr. 1998:52:826-31.

7. Joshi K, Avasthi A, Kumar R. Health related quality of life (HRQOL) among elderly in Northern India. Health Population Perspectives Issues. 2003;26(4): 141-53.

8. Ng TP, Broekman BF, Niti M, Gwee X, Kua E. Determinants of successful aging using a multidimensional definition among Chinese elderly in Singapore. Am J Geriatr Psychiatry. 2009;17(65):407-16.

9. Sweed HS. Population Ageing - Egypt Report. Middle East Journal of Age and Ageing. 2016; 13(2).

10. WHO. World report on ageing and health. Geneva: World Health Organization; 2015.

11. Brucki SN, Caramelli P, Bertolucci P, IH. O. Suggestions for utilization of the mini-mental state examination in Brazil. Arq Neuropsiquiatr. 2003;61(3B): 777-81.

12. Hamilton M. Rating depressive patients. J Clin Psychiatry. 1980;41:21-4.

13. Farghaly M, Hussein M, Hassan A, Hegazy M, Sabbah A. Testing of Verbal Fluency in Egyptians: Cultural and Educational Challenges. Cogn Behav Neurol. 2018;31(3):133-41.

14. Benton A, Sivan A, Hamsher K, Varney N, Spreen O. Contributions to neuropsychological assessment. 2nd ed. New York: Oxford University Press; 1994

15. Ware JJ, Sherbourne C. The MOS 36-Item Short-Form Health Survey (SF36): I. Conceptual Framework and Item Selection. Med Care. 1992;30:473-83.

16. Coons SJ, Alabdulmohsin SA, Draugalis JR, Hays RD. Reliability of an Arabic Version of the RAND-36 Health Survey and Its Equivalence to the US-English Version. Med Care. 1998;36(3):428-32.
17. Buysse D, Reynolds C III, Monk T, Berman S, Kupfer D. The Pittsburgh Sleep Quality Index: A new instrument for psychiatric practice and research. J Psychiatr Res. 1989;28(2):193-213.

18. Suleiman K, Yates BC, Berger AM, Pozehl B, Meza J. Translating the Pittsburgh Sleep Quality Index Into Arabic. West J Nurs Res. 2010;32(2):250-68.

19. Kaiser M, Bauer J, Ramsch C, Uter W, Guigoz Y, Cederholm T, et al. Validation of the Mini Nutritional Assessment Short-Form (MNA ${ }^{\oplus}$-SF): A practical tool for identification of nutritional status. J Nutr Health Aging. 2009;13:782-8.

20. Lundervold AJ, Wollschläger $\mathrm{D}$, Wehling $\mathrm{E}$. Age and sex related changes in episodic memory function in middle aged and older adults. Scand J Psychol. 2014;55(3):225-32.

21. Kerchner GA, Racine CA, Hale S, Wilheim R, Laluz V, Miller BL, et al. Cognitive Processing Speed in Older Adults: Relationship with White Matter Integrity. PLoS ONE. 2012;7(11):e50425.

22. Rathee R, Rallabandi VP, Roy PK. Age-Related Differences in White Matter Integrity in Healthy Human Brain: Evidence from Structural MRI and Diffusion Tensor Imaging. Magn Reson Insights. 2016;9:9-20.

23. Shao Z, Janse E, Visser K, Meyer AS. What do verbal fluency tasks measure? Predictors of verbal fluency performance in older adults. Front Psychol. 2014;5:772.

24. Duff K, Schoenberg M, Mold J, Scott J, Adams R. Gender differences on the Repeatable Battery for the Assessment of Neuropsychological Status subtests in older adults: baseline and retest data. J Clin Exp Neuropsychol. 2011;33:448-55.

25. Wiederholt W, Cahn D, Butters NM, Salmon DP, Kritz-Silverstein D, BarrettConnor E. Effects of age, gender and education on selected neuropsychological tests in an elderly community cohort. J Am Geriatr Soc. 1993:41:639-47.

26. Snitz B, Unverzagt F, Chang C, Bilt J, Gao S, Saxton J, et al. Effects of age, gender, education and race on two tests of language ability in communitybased older adults. Int Psychogeriatr. 2009:1051-62.

27. Lima MG, Barros MB, César CL, Goldbaum M, Carandina L, Ciconelli RM. Health related quality of life among the elderly: a population-based study using SF36 survey. Cad Saude Publica. 2009;25(10):2159-67.

28. Aghamolaei T, Tavafian SS, Zare S. Health Related Quality of Life in Elderly People Living in Bandar Abbas, Iran: A Population-Based Study. Acta Medica Iranica. 2010:48(3):185-91.

29. Boman E, Häggblom A, Lundman B, Nygren B, Fischer RS. Identifying variables in relation to health-related quality of life among communitydwelling older women: Knowledgebase for health-promoting activities. Nordic Journal of Nursing. 2016;36(1):20-26.

30. Ibrahim ZM, Sayed Ahmed WA. El-Hamid SA, vol. 42. Clin Exp Obstet Gynecol: Prevalence of menopausal related symptoms and their impact on quality of life among Egyptian women; 2015. p. 161.

31. Elsabagh EE, Abd AE. Menopausal symptoms and the quality of life among pre/post menopausal women from rural area in Zagazig city. Life Sci J. 2012;283:9.

32. Yakout S, Kamal S, Moawed S. Menopausal Symptoms and Quality of Life among Saudi Women in Riyadh and Taif. J Am Sci. 2011;7:778.

33. Prakash RS, Voss MW, Erickson Kl, Kramer AF. Physical activity and cognitive vitality. Annu Rev Psychol. 2015;66:769-97.

34. Kim MH, Han KS, Park MS. A study on the sleep quality of the patients with temporomandibular disorders using Pittsburgh sleep quality index. J Korean Acad Oral Med. 2002:89-105.

35. Lim A, Kowgier M, Yu L, Buchman A, Bennett D. Sleep fragmentation and the risk of incident alzheimer's disease and cognitive decline in older persons. Sleep. 2013;36(10):1027-32.

36. Hinz A, Glaesmer H, Brähler E, Löffler M, Engel C, Enzenbach C, et al. Sleep quality in the general population: psychometric properties of the Pittsburgh Sleep Quality Index, derived from a German community sample of 9284 people. Sleep Med. 2017;30:57-63.

37. Gaus SE, Strecker RE, Tate BA, Parker RA, Saper CB. Ventrolateral preoptic nucleus contains sleep-active, galaninergic neurons in multiple mammalian species. Neuroscience. 2002;115:285-94.

38. Madrid-Valero JJ, Martínez-Selva JM. Ribeiro do Couto B, Sánchez-Romera JF, Ordoñana JR. Age and gender effects on the prevalence of poor sleep quality in the adult population. Gac Sanit. 2017:18-22.

39. Mahfouz E, Mohammed E, Abd-el RT. Assessment of nutritional statutes of elderly population in rural Minia, Egypt. J Aging Res Clin Practice. 2013;2(3):300-2 
40. Ghimire S, Baral B, Callahan K. Nutritional assessment of communitydwelling older adults in rural Nepal. Plos One. 2017;12(2):e0172052.

41. Majumder M, Saha I, Chaudhuri D. Assessment of nutritional risk in community-dwelling older adults (65 to 75 years) in Kolkata, India. J Nutr Gerontol Geriatr. 2014;33(2):126-34.

42. Cuervo M, García A, Ansorena D, Sánchez-Villegas A, Martínez-González M, Astiasarán I, et al. Nutritional assessment interpretation on 22,007 Spanish community-dwelling elders through the Mini Nutritional Assessment test. Public Health Nutr. 2009;12(1):136

43. Vellas B, Guigoz Y, Baumgartner M, Garry PJ, Lauque S, Albarede JL. Relationships Between Nutritional Markers and the Mini-Nutritional Assessment in 155 Older Persons. J Am Geriatr Soc. 2000;48(10):1300-9.

44. Agarwalla R, Saikia AM, Baruah R. Assessment of the nutritional status of the elderly and its correlates. J Family Community Med. 2015;22(1):39-43.

45. Boulos C, Salameh P, Barberger-Gateau P. The AMEL study, a cross sectional population-based survey on aging and malnutrition in 1200 elderly Lebanese living in rural settings: protocol and sample characteristics. BMC Public Health. 2013;13:573.

46. Orsitto G. Different components of nutritional status in older inpatients with cognitive impairment. J Nutr Health Aging. 2012:468-71.

47. Khater $\mathrm{M}$, Abouelezz $\mathrm{N}$. Nutritional status in older adults with mild cognitive impairment living in elderly homes in Cairo, Egypt. J Nutr Health Aging. 2011:104-8.

48. Dauncey M. Nutrition, the brain and cognitive decline: insights from epigenetics. Eur J Clin Nutr. 2014:1179-85.

\section{Publisher's Note}

Springer Nature remains neutral with regard to jurisdictional claims in published maps and institutional affiliations.

\section{Submit your manuscript to a SpringerOpen ${ }^{\circ}$ journal and benefit from:}

- Convenient online submission

- Rigorous peer review

- Open access: articles freely available online

- High visibility within the field

- Retaining the copyright to your article

Submit your next manuscript at $\boldsymbol{\nabla}$ springeropen.com 